\title{
TEATRO NA ESCOLA: A REINVENÇÃO DO ESPAÇO VIGIADO
}

\author{
Danielle Rodrigues de Moraes $^{1}$
}

\section{Resumo}

Com a publicação da LDB no 9394/96, a arte foi reconhecida como área de conhecimento no currículo escolar, possibilitando ao teatro um espaço na escola, como linguagem artística a ser trabalhada na disciplina Arte. Este artigo enfoca, a partir do referencial teórico de Michel de Certeau, como perceber o teatro como um movimento tático de reinvenção do cotidiano escolar, a partir de suas "maneiras de fazer".

Palavras-chave: escola, teatro-educação, tática.

\section{Abstract}

The publication of LDB 9394/96, art has been recognized as an area of knowledge in the school curriculum, giving a space to the theater in the school, as an artistic language to be worked in the field of Art. This article, taking Michel de Certeau as a theoretical reference, focuses on theater as a tactical move towards the reinvention of the everyday school life through the "arts of doing".

Keywords: school, theatre-education, tactics. 
Acreditar no mundo significa principalmente suscitar acontecimentos, mesmo pequenos, que escapem ao controle, ou engendrar novos espaçostempos, mesmo de superfície ou volume reduzidos.

Gilles Deleuze

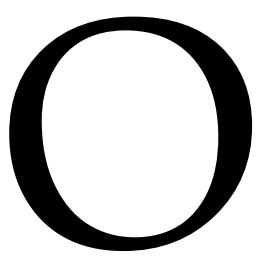
teatro na escola, como linguagem artística, vem a ser formalmente implementado através da disciplina Arte $^{2}$, que se tornou parte do currículo obrigatório escolar, a partir das Leis de Diretrizes e Bases (LDB) de 1996, n 9394 (BRASIL, 2009). Este artigo focaliza como o teatro como ensino nas escolas, a partir das sugestões dos Parâmetros Curriculares Nacionais - PCNs (BRASIL, 1998).

Como ponto de partida, é possível perceber que o ensino do teatro se diferencia das demais práticas educacionais escolares. A forma de exercício-resposta, a avaliação e pontuação através de erros e acertos, exemplos do ensino tradicional, onde o aluno permanece sentado, ouvindo o professor e copiando matéria, ainda estão presentes e consolidados nos ambientes escolares. O teatro, entretanto, precisa de um espaço que aberto a experiências que envolvem o corpo, o movimento, os jogos.

Assim, a distinção entre o modelo de ensino utilizado nas demais disciplinas e o modelo de ensino em que o teatro opera, são destoantes em si. Se o fazer teatral exige uma disciplina para o domínio de suas técnicas, ele também propõe a transgressão do cotidiano.

No contexto da escola, o teatro e as demais artes, encontram como resistência a normatização da instituição, através

1 Mestre em Educação pela UFSJ (Universidade Federal de São João del Rei/MG) , com pesquisa na área de Teatro e Educação. Experiência com teatro nas escolas públicas de Minas Gerais e com oficinas extracurriculares em escolas da rede particular de ensino. Atualmente é instrutora de Artes Cênicas do Centro de Referência de Assistência Social (CRAS), em São João del Rei e assistente do grupo de estudos sobre "Jogo, Arte-Educação e Sustentabilidade" do PIBID do curso de Teatro da UFSJ.

2 Os PCNs designaram Arte com letra maiúscula para se tratar da área curricular; nos demais casos, arte com letra minúscula. do disciplinamento dos corpos. Essa normatização escolar, que propicia a não-movimentação corpórea, possibilita uma educação do corpo. Como afirma Strazzacappa:

O corpo está em constante desenvolvimento e aprendizado. Possibilitar ou impedir o movimento da criança e do adolescente na escola; oferecer ou não oportunidades de exploração e criação com o corpo; despertar ou reprimir o interesse pela dança no espaço escolar, servir ou não de modelo... de uma forma ou de outra estamos educando corpos. Nós somos nosso corpo. Toda educação é educação do corpo. A ausência de uma atividade corporal também é educação do corpo: a educação para o não-movimento - educação para a repressão. Em ambas as situações, a educação do corpo está acontecendo. O que diferencia uma atitude da outra é o tipo de indivíduo que estaremos formando (STRAZZACAPPA, 2001, p. 79).

No caso do teatro, o corpo é um instrumento de trabalho que requer a "vivência do momento, em sua presença expressiva, materializando (...) os pensamentos, as reflexões, as sensações e os sentimentos. (PEDROSO, 2007, p.3). Estar presente em uma situação, é experiênciála, comunicar-se com o aqui e agora da existência. Como afirma Merleau-Ponty (1999, p.142), "ser uma consciência, ou antes, ser uma experiência, é comunicar interiormente com o mundo, com o corpo e com os outros, ser com eles ao invés de estar ao lado deles".

Como instrumento capaz de propiciar ao aluno uma educação estética calcada na experienciação, o teatro favorece uma relação sensível e direta com o outro; uma ampliação da percepção, a partir da experimentação: "a educação plena do indivíduo que leva em consideração o ser humano como um todo articulado, física, mental, emocional, política e espiritualmente" (SOARES, 2010, p.19).

Para tanto, o fazer teatral depende da interação entre alunos, entre estes e o professor, da construção de ideias em grupo, do movimento, da exposição de opiniões. 
Só assim a aprendizagem deixará de ser um mero acúmulo de informações, o que Freire nos apresenta como "educação bancária":

quanto mais vai "enchendo" os recipientes com seus "depósitos", tanto melhor o educador será. Quanto mais se deixem docilmente "encher", tanto melhores educandos serão. Desta maneira, a educação se torna um ato de depositar, em que os educandos são os depositários e o educador o depositante (FREIRE, 1983, p. 66).

Para Soares (2010), "garantir um espaço de criação dentro da escola exige o esforço consciente do professor para não se render às armadilhas sutis do sistema que desmobiliza as energias, a confiança, o entusiasmo e o compromisso de todos" (p.26). Talvez, neste ponto, seja possível dizer que algumas questões enfrentadas pelo professor de teatro são similares aos desafios encontrados pelo corpo escolar como um todo.

Sendo assim, para estas reflexões, utilizarei algumas ideias de Foucault (1997), para apresentar o cotidiano do teatro na escola, inserido em um espaço disciplinar, e indicar como a linguagem cênica tem condições de reinventar esse cotidiano, através de metodologias que promovem uma forma diferente de se lidar com o conhecimento. Segundo Michel de Certeau (1994) a abordagem do processo teatral como uma prática de ensino-aprendizagem diferenciada frente às ordens e regras já instauradas no cotidiano escolar, pode ser tomada enquanto tática. Para De Certeau, nem todos os sujeitos são obedientes; o autor destaca que nem todos os indivíduos consomem e se relacionam com o que está imposto da mesma forma.

\section{O lugar e o espaço do teatro na escola}

De acordo com Foucault (1997), a construção de lugares, como as instituições, passa por tecnologias de poder, como parte integrante da tentativa da organização espacial, onde mecanismos de transmissão de conhecimento representam, na realidade, uma estratégia de sujeição, disfarçada por atribuições de favorecimento do progresso intelectual, social e da mobilidade socioeconômica. Propostas sociais, como prisões, políticas públicas de saúde, educação, são saberes estratégicos de controle capazes de organizar a vida de uma sociedade, refletidas na construção de lugares, com o intuito de controlar o tempo e o saber dos indivíduos.

Para De Certeau (1990), as instituições são estratégias de dominação, no entanto, não acontecem a partir de uma prática passiva e dominante, ocorrida por um conformismo dócil às imposições do mercado e dos poderes sociais. No consumo cultural e material do cotidiano, há apropriações que fogem da ordem do controle. Mesmo participando das normas de um lugar, é possível proceder de outras formas, por meio de procedimentos "multiformes, resistentes, hábeis e obstinad os que fogem à disciplina sem estar por isso fora do campo em que a mesma se exerce" (p.146).

A escola, enquanto instituição, pode ser definida como lugar de estratégias, que mede, observa e controla. Nela desconfiase do que pode tirar a ordem. Tenta-se coordenar, ao máximo, toda a situação espacial, tornando-se o lugar, estratégia de dominação visual. As condutas são vigiadas para que não haja seu desvio. Quando este acontece, é preciso corrigi-lo e reestabelecê-lo. Resta saber qual o lugar do teatro nesse lugar vigiado que é a escola.

De Certeau (1990) aponta uma dinâmica entre espaço/lugar, afirmando lugar como uma configuração instantânea de posição, implicando uma indicação de estabilidade, e o espaço como um lugar praticado, sendo que a interatividade entre os dois termos acontece incessantemente. Habitantes a todo instante transformam lugares em espaços e espaços em lugares; mesmo assim, entre espaço e lugar, o autor coloca uma distinção que delimitará um campo: 
Um lugar é uma ordem (seja qual for) segundo a qual se distribuem elementos nas relações de coexistência. Aí se acha, portanto, excluída a possibilidade, para duas coisas, de ocuparem o mesmo lugar. Aí impera a lei do 'próprio': os elementos considerados se acham uns ao lado dos outros, cada um situado num lugar 'próprio' e distinto que o define. [...] O espaço é o cruzamento de móveis. É de certo modo animado pelo conjunto dos movimentos que aí se desdobram. Espaço é o efeito produzido pelas operações que o orientam, o circunstanciam, o temporalizam e o levam a funcionar em unidade polivalente de programas conflituais ou de proximidades contratuais (DE CERTEAU, 1990, p. 201-202).

Para o autor, as noções de "lugar" espaço próprio, e "espaço" - lugar praticado, fazem parte de um mesmo processo. Um lugar é, portanto, uma configuração de posição; ao mesmo tempo, esse lugar, espaço ocupado, carrega consigo as relações entre os indivíduos que ali convivem, fazendo dele um lugar praticado.

A inclusão do teatronocurrículoescolar aconteceu mediante uma luta com avanços e recuos de arte-educadores por um espaço para a arte no ambiente escolar. No entanto, esse espaço foi conquistado a partir do poder político, segundo André, a partir de uma lei que representa necessidades sociais gerais, não sendo o lugar desse movimento o da cultura nem o da educação:

os educadores e artistas atuam no lugar dominado pelo poder político. O que é conseguir a aprovação de uma lei que beneficia a permanência das artes no ambiente escolar senão uma negociação entre um proprietário - as forças políticas e econômicas que estariam representando necessidades sociais gerais - e um desapropriado - o artista (no espaço da cultura) e o educador (no ambiente escolar) que estaria representando necessidades sociais específicas? O que se consegue nessa situação é a permissão de ações julgadas apropriadas àquele lugar, julgadas por seu proprietário. [...] Cabe a artistas e educadores compreender que talvez não seja possível identificar-se com as ações dos papéis sociais que são obrigados a vestir (ANDRÉ, 2007, p. 137).
A arte foi legitimada como área de conhecimento e, nesse sentido, possui um lugar no ambiente escolar. Mas, nãoé por ter a lei a seu favor que o teatro tem seu espaço garantido e valorizado - a lei indica apenas sua situação ou posição determinada, mas não lhe assegura a sua utilização, pois esta se dá a partir da ocupação desse lugar, da possível transformação do lugar conquistado em espaço utilizável.

O teatro na escola ainda se encontra em um momento de adaptação, em uma posição que requer melhor compreensão de seu papel. Depende da ação dos professores para que aconteça, e essa ação precisa ser construída. $\mathrm{O}$ preparo dos professores é fundamental tanto para a argumentação, nas reuniões com os pares e cargos dirigentes das escolas, quanto em sua atuação no campo do ensino. Assim, seja o teatro o conteúdo da disciplina Arte ou um projeto extracurricular, ele circunscreve seu espaço.

Quando o teatro é levado ao espaço escolar encontra um ponto de resistência, a tentativa da normatização. Como aponta Leite,

a relação entre a produção artísticocultural e a instituição de ensino - seja ela espaço de educação infantil, escola ou universidade - é, por princípio, conceitual, conflituosa. Se, por um lado, a área artística tem na transgressão a mola propulsora de sua construção, as instituições acima citadas pautam-se na normatização. Como, então, favorecer um espaço de transgressão e criação, de formação de sentidos e significados no interior dessas instituições? Como trabalhar cercado de grades curriculares? Organização em seriação? (apud STRAZZACAPPA, 2008, p. 81).

A normatização é produzida pela disciplina, pelo controle dos corpos, em uma escala evolutiva e gradual; busca um aumento das potencialidades do indivíduo no sentido de sua utilidade, visando "não unicamente o aumento de suas habilidades, nem tampouco aprofundar sua sujeição, mas a formação de uma relação que no mesmo mecanismo 
o torna tanto mais obediente quanto é mais útil, e inversamente" (FOUCAULT, 1997, p. 119). Assim, gera subsídios para o aperfeiçoamento das técnicas disciplinares, enraizadas em preceitos de docilidade, de assujeitamento.

Os assujeitados, afirma Certeau (1990), são indivíduos sem lugares próprios, mas é possível transformar e reinventar a vida diária a partir de "maneiras de fazer", "astúcias sutis", "táticas de resistência", ações próprias dos que conseguem, mesmo estando dentro de um espaço normatizado, driblar a vigilância. $\mathrm{O}$ cotidiano seria um momento possível para as microrresistências, passível de deslocar e subverter relações de poder. Essa subversão põe em confronto o estabelecimento de uma rede de forças, abrindo a possibilidade de transformação. A obediência não é algo passivo, diz o autor, onde há estratégia, há tática, a qual possibilita a formação do não-dominado, do não-planejado, transformando o lugar em um espaço que foge das regras preestabelecidas, podendo resultar em produção de outra cultura e de um espaço independente. Enquanto a estratégia requer o poder, a tática é determinada pela ausência do poder, sendo uma forma de perceber as falhas da administração vigilante.

A tática, "ação calculada pela ausência de um próprio", é o movimento no espaço controlado, é a ação da astúcia, daquele que, mesmo no espaço marcado, consegue burlar a ordem imposta e efetivar conquistas. Sua mobilidadeé permitida por seu não-lugar. Ela capta e aproveita as possibilidades surgidas em um instante, conseguindo estar onde ninguém espera. “Tem que utilizar, vigilante, as falhas que as conjunturas particulares vão abrindo na vigilância do poder proprietário" (DE CERTEAU, 1990, p. 101).

Assim, para De Certeau (1990), as ações são classificadas como estratégias, quando exercidas a partir do poder, capazes de articular a distribuição de forças, e como táticas, quando traçam trajetórias indeterminadas, a partir de uma sutileza que espera pela ocasião, para subverter o lugar do outro, sendo ação do fraco. A tática, para o autor, é a arte do fraco, pois quanto maior um poder, no caso da estratégia, tanto menos permissão pode ser dada para mobilizar efeitos de astúcia. A seriedade da ação direta do poder não permite espaço para esse jogo.

As estratégias requerem um "próprio", um lugar passível de ser limitado como algo próprio, um lugar ordenado por técnicas que organizam sistemas, um espaço possível de ser controlado e organizado, possível de reconhecer "um tipo específico de saber, aquele que sustenta e determina o poder de conquistar para si um lugar próprio" (DE CERTEAU, 1990, p. 100). Por outro lado, as táticas são ações articuladas pela ausência de um "próprio". Como não têm espaço, nem meios para se manterem, movimentam-se e multiplicam-se no espaço controlado.

A tática não tem por lugar senão o do outro, por isso, deve jogar com o terreno que lhe é imposto tal como o organiza a lei de uma força estranha. [...] Este não-lugar lhe permite sem dúvida mobilidade. [...] Tem que utilizar, vigilante, as falhas que as conjunturas particulares vão abrindo na vigilância do poder proprietário. Aí vai caçar. Cria ali surpresas. Consegue estar onde ninguém espera. É astúcia (DE CERTEAU, 1990, p. 100).

As táticas não obedecem à lei do lugar, postulam um "fazer com", o que De Certeau (1990) designa de "usos" (p. 93). Sua ação organiza o trabalho silenciosamente, com inventividade própria. E é por meio dessa lógica que é possível intervir na ordem imposta, fazer esta funcionar em outro registro, conservar sua diferença no próprio espaço organizado pelo ocupante, inventando a partir do que já está estabelecido.

30 conceito de "próprio" em De Certeau se refere à estabilidade, a qualquer estrutura situada e organizada em um tempo e espaço, que caracterize, com nome e contornos definidos, uma identidade. Pode ser uma instituição científica, uma entidade comercial, uma cidade,umexércitoe,atémesmo,umindivíduocujocomportamento coincida com as definições de estratégia propostas pelo autor 
A partir da LDB de 1996, a arte é legitimada como campo de conhecimento na educação. No entanto, essa ainda não seria uma conquista, o teatro vive uma situação daquele que não tem lugar, pois para ser trabalhado, como já foi dito antes, depende da ação do educador. Talvez, aí esteja a lacuna a ser preenchida - diante de um espaço vigiado, com procedimentos técnicos minúsculos, tentar jogar com os mecanismos da disciplina, não se conformando com estes, a não ser para a sua alteração.

Se é verdade que por toda parte se estende e se precisa a rede da 'vigilância', mais urgente ainda é descobrir como é que uma sociedade inteira não se reduz a ela: que procedimentos populares (também 'minúsculos' e cotidianos) jogam com os mecanismos da disciplina e não se conformam com ela a não ser para alterálos; enfim, que 'maneiras de fazer' formam a contrapartida, do lado dos consumidores (ou 'dominados'?), dos processos mudos que organizam a ordenação sociopolítica (DE CERTEAU, 1990, p. 41).

Essas "maneiras de fazer", como práticas inventivas, como gestos criativos de um não-conformismo, ao mesmo tempo em que são exercidas, têm a possibilidade de burlar a ordem, de resistir às disposições das coisas, transgredindo o que está posto, institucionalizado. Têm característica inovadora por conseguir gerar novas formas, jogando com a ordem imposta e encontrando brechas nesse esquema que lhe possibilitam escapar silenciosamente do que está posto. Deacordo com Machado, um bom exemplo desse jogo pode ser dado por intermédio de uma pessoa que aluga um apartamento. "Conquanto o proprietário seja o dono do imóvel, o inquilino ocupa o lugar como seu. Distribui os móveis, cria ambientes, enfim, institui a sua maneira de viver em um espaço que pertence a outro" (2004, p. 75).

A invenção, a partir da tática, pode acontecer dentro ou fora do ambiente escolar, de acordo com o jogo estabelecido entre quem propõe e quem participa.
Segundo Callois, “todo jogo é um sistema de regras que determina o que é e o que não é do jogo, ou seja, o permitido e o proibido" (1986, p. 12). O jogo faz com que o jogador interiorize as regras para penetrar no universo lúdico da atividade. As regras precisam ser seguidas, pois sua violação acarreta a destruição da atividade. A presença de certos limites é incontestável na prática de qualquer jogo. No entanto, o jogador sempre tem relativa liberdade de criação, pois, como o jogo não acontece no tempo da vida real, pode-se correr alguns riscos sem grandes consequências para o participante.

Para Huizinga, o jogo também inclui delimitação, ordem, desinteresse e liberdade. Todo jogo é realizado em um campo previamente delimitado, com espaço e tempo restritos, resultado das regras determinadas e da obediência dos jogadores às mesmas. "O jogo cria ordem e é ordem (...) é uma atividade desligada de qualquer interesse material, praticada dentro de limites espaciais e temporais próprios, segundo certa ordem e certas regras" (2008, p. 13-16).

Os espaços sociais delimitam um jogo, impondo regras e valores, a partir do qual há consentimento do homem, mas não conformidade:

As artes de fazer são ações de não conformidade silenciosa, de um sujeito que reconhece o jogo e suas regras, mas procura, nas jogadas do outro, brechas nas quais pode tirar vantagem. É um movimento de embate sem enfrentamento direto dentro de um território ocupado (MACHADO, 2004, p. 99).

$\mathrm{Na}$ instituição escolar, enquanto o ato estratégico organiza o lugar, por meio de suas normas e regras, a tática se mobiliza, mostrando que há formas diferentes de se apropriar desses lugares. Se há a microfísica do poder atuando, desde a construção arquitetônica de um lugar até o corpo do indivíduo, também há a micro - resistência, mobilizadoradeaçõesinesperáveis, possível de perpassar as fronteiras da dominação, 
conseguindo estar onde ninguém espera, sendo astúcia. Recursos são utilizados bem debaixo do nariz do poder, convertendo-se em subversão silenciosa (DE CERTEAU, 1990). A tática surge e desaparece como uma partida de jogo. Este, possuindo certa relatividade temporal, dura enquanto sua ação continuar; o resultado de uma partida se encontra em suspensão e garante a manutenção da própria atividade lúdica.

Essa possibilidade tática está no fazer teatral, que permite uma mobilidade de ensino e um processo de construção de conhecimento que foge às regras do que já está imposto, pois sua ação educativa traz embutida a imprevisibilidade de criação no momento da aprendizagem, e a possibilidade de se construir o espaço praticado da uma relação sólida entre teatro e educação.

\section{Referências bibliográficas}

ANDRÉ, Carminda Mendes. O teatro pós-dramático na escola. 2007. 206 p. Tese (Doutorado)-Programa de Pós-Graduação em Educação, Universidade de São Paulo, São Paulo, 2007.

BRASIL. Secretaria de Educação Fundamental. Parâmetros Curriculares Nacionais: arte $\left(5^{\mathrm{a}}\right.$ a $8^{\mathrm{a}}$ séries). Brasília: MEC/SEF, 1998.

- Ministério da Educação. Lei $n^{o}$ 9.394/96. Disponívelem:<www.portal.mec. gov.br/seed/arquivos/pdf/tvescola/ leis/lein9394.pdf>. Acesso em: 18 abr. 2009, 16:28 min.

CAILLOIS, Roger. Los juegos e los hombres: la máscara y el vértigo. México: Fondo de Cultura Económica, 1986.

DE CERTEAU, Michel. A invenção do cotidiano. 9. ed. Petrópolis: Vozes, 1990.

FOUCAULT. Michel. Vigiar e Punir. 32. ed. Petrópolis: Vozes, 1997.

FREIRE, Paulo. Pedagogia do oprimido. 13. ed. Rio de Janeiro: Paz e Terra, 1983.

HUIZINGA, Johan. Homo Ludens: o jogo como elemento da cultura. 5. ed. São Paulo: Perspectiva, 2008.
MACHADO, Joceleia Cleusa. Fazer teatro na escola... por que não? Estudo sobre a produção teatral no espaço escolar. 2004. 185 p. Dissertação (Mestrado)- Instituto de Artes, Universidade Estadual de Campinas, Campinas, 2004.

MERLEAU-PONTY, Maurice. Fenomenologia da percepção. 2. ed. São Paulo: Martins Fontes, 1999.

SOARES, Carmela. Pedagogia teatral, uma poética do efêmero: o ensino do teatro na escola pública. São Paulo: Hucitec, 2010.

STRAZZACAPPA, Márcia. A arte do espetáculo vivo e a construção do conhecimento: vivenciar para aprender. In: FRITZEN, Celdon; MOREIRA, Janine (Org.). Educaçãoe Arte, as linguagens artísticas na formação humana. Papirus: Campinas, 2008. p. 77-94. 